\title{
Fatal pulmonary embolism following compression sclerotherapy for varicose veins
}

\author{
P. MCMASTER \\ F.R.C.S.
}

\author{
W. G. Everett \\ M.Ch., F.R.C.S., F.R.C.S.(Ed)
}

Addenbrooke's Hospital, Cambridge

\section{Summary}

A case of fatal pulmonary embolism following compression sclerotherapy treatment of varicose veins is reported. This is the first death following this form of treatment recorded.

DEEP vein thrombosis and subsequent pulmonary embolism is a recognized, though infrequent complication of surgical treatment of varicose veins. Pulmonary embolism following compression sclerotherapy is uncommon and no fatal case has previously been reported (Fegan, 1970).

\section{Case report}

A 36-year-old housewife was referred by her general practitioner to the outpatient department in September 1970. She gave a 10 year history of discomfort in her right calf on prolonged standing and slight ankle swelling towards the end of the day. There was no significant past medical history. Two pregnancies had been uneventful and there had been no previous episode suggesting deep vein thrombosis. She was not taking oral contraceptives.

Routine examination revealed no medical disorders, but she was a little overweight $(9$ st $12 \mathrm{lb}$, height $\left.5^{\prime} 4^{\prime \prime}\right)$. Examination of her legs showed the presence of varicose veins in her right leg in the region of the knee and upper calf. There was no sapheno-femoral incompetence. By palpation three incompetent veins were detected, one $10 \mathrm{~cm}$ above the knee on the medial aspect of the thigh and two in the upper calf. Pressure at these points controlled the varices.

Each of the incompetent perforator sites was injected with $0.5 \mathrm{ml}$ sodium tetradecyl acetate $3 \%$ with the leg in elevation and the veins empty. Two small varicose veins, unconnected with the main incompetent system, on the lateral aspect of the calf were also injected. A total of five injections was therefore given. Compression was maintained with foam pads and the leg bandaged in elevation. The bandages extended from foot to upper thigh and were said to be comfortable at the end of the procedure.

Detailed instructions, both verbal and written, were given to the patient about exercise during the period of treatment.

The patient attended her general practitioner 2 days later complaining of mild discomfort in her calf. The bandages required no adjustment. The patient was then apparently well and active until she suddenly collapsed and died $\mathbf{1 0}$ days after treatment.

At post-mortem examination the cause of death was found to be pulmonary embolism. Both main lobar divisions of the pulmonary artery were obstructed by embolic ante-mortem thrombi. A careful examination of the legs revealed slight swelling of the right calf. There was evidence of venous thrombosis in the deep veins of the right calf. Examination of the actual site of injection revealed no local thrombotic changes in the veins.

\section{Discussion}

The popularity of injection techniques in the treatment of varicose veins has fluctuated since its introduction (Linser, 1911, 1916). More recently it has been shown that compression sclerotherapy is a logical and effective form of treatment in selected cases (Sigg, 1952; Fegan, 1963). Large series of patients have now been successfully treated and complications are uncommon (Hobbs, 1968).

In this case the standard injection technique was followed (Fegan, 1963) and compression bandages applied accordingly.

There appear to be two major factors concerned in this technique which might increase the risk of deep vein thrombosis. The injection technique itself and the interference with deep venous blood flow.

The spillage of sodium tetradecyl acetate into the deep venous system is usually in such small amounts and is so quickly dispersed that thrombosis does not occur. However, if the flow in the deep system is slowed then its removal will be hindered. 
The interference with deep venous blood flow may be brought about by inexpert bandaging. The importance of a meticulous and practical bandaging technique has recently been re-emphasized (Fegan, 1971).

In addition, many patients feel that a bandaged limb should be 'rested'. Inactivity of the calf muscle pumps appreciably slows the rate of deep venous return. We give detailed instructions to our patients about increasing their activities, especially walking, during the period of treatment. We have not previously insisted that they walk 2 to 3 miles immediately following treatment, as do some clinics (Fegan, 1967) Nevertheless, it may be significant that in this case, almost immediately following treatment, the patient had a long car journey to return home. This subsequent inactivity would appear to have appreciably increased the risk of deep venous thrombosis.
References

FEGAN, W.G. (1963) Continuous compression technique of injecting varicose veins. Lancet, ii, 109.

FEgAN, W.G. (1967) Varicose Veins-Compression Sclerotherapy. Heinemann, London.

Fegan, W.G. (1971) The art of bandaging the lower limb? British Journal of Hospital Medicine, 5, 697.

FEgan, W.G. (1970) Personal communication.

Hoввs, J.T. (1968) The treatment of varicose veins. British Journal of Surgery, 55, 777.

LINSER, P. (1911) Quoted by DzIACzKowsKı, I. (1960) $\overrightarrow{0}$ Therapy of thrombophlebitis with Butazolidin. Polsik Tygodnik Lekarski, 14, 1911.

Linser, P. (1916) Veber die Konservative Behandlung dero Varium. Medizinische Klinik, 12, 897.

SIGG, K. (1952) Treatment of varicose veins and accom panying complications. Angiology, 3, 355 .

\section{Pulmonary reaction to Furoxone}

\author{
J. V. Collins \\ M.B., M.R.C.P.
}

\section{A. L. THOMAS \\ M.B., M.R.C.P.}

\section{Summary}

A patient is reported in whom an acute pulmonary reaction resulted from the ingestion of Furoxone (furazolidine), a member of the nitrofurantoin group of drugs. A positive lymphocyte transformation test to Furoxone was found. This is thought to suggest that Type IV (Gell \& Coombs, 1968) thymus dependent hypersensitivity may be implicated in such pulmonary reactions.

WHEN a patient develops what is suspected to be a hypersensitivity reaction to a drug, the problem of identifying the drug responsible becomes more difficult as the number and variety of drugs available for prescription increases. It has been shown that between $5-10 \%$ of patients admitted to hospital experience some toxic or hypersensitivity reaction to a drug (Reeves \& Trounce, 1971). Antibiotics, hypnotics and tranquillizers are the drugs most likely to produce such reactions (MacDonald \& Mackay, 1964). We report a patient in whom a respiratory illness complicated drug therapy for an unrelated condition.

Reprint requests to: Dr J. V. Collins, St Bartholomew's Hospital, London, E.C.1A 78E.

\section{Case history}

The patient, K.P., a man aged 56 years, was admitted to St Olave's Hospital on 23 March 19713 with a 12-day history of fever, rigors, generalized rash and night sweats associated with general malaise.: From September 1970, he had been complaining of severe low back pain, which after extensive investiga -3 tion was found to be due to osteomyelitis of $\mathrm{L} 3 / 4.0$ This was treated with a 5-week course of cloxacillin (3-chlorophenyl-5-methyl-4-isoxazolyl penicillin) until 11 February 1971. His back pain improved and his ESR fell. He travelled to Tangier for a convales응 cent holiday and 5 days later he developed nauseas and anorexia after meals, without vomiting or? diarrhoea. He returned to England on 28 February 1971 , and because of persistence of these symptoms he suspected that he had a gastro-intestinal infection 5 and treated himself with Furoxone (3-(5-nitrow furfurylideneamino)-2-oxo-oxazolidine) for 5 days finishing on 9 March 1971. 2 days later he becameo febrile with rigors and breathlessness. His back paino returned and on 11 March 1971 he took $500 \mathrm{mg}$ of ampicillin ( $\alpha$-amino benzyl penicillin). The followingo day he had a generalized urticarial scarlatiniforme rash. He changed immediately to Floxapen (flucloxa 